\title{
Características químicas de solo submetido ao tratamento com esterco líquido de suínos e cultivado com gramíneas forrageiras
}

\author{
Chemical characteristics of soil submitted swine liquid manure treatment and \\ cultivated with forage grasses
}

\author{
Flávia Martins de Queiroz ${ }^{1}$ Antônio Teixeira de Matos ${ }^{2}$ Odilon Gomes Pereira ${ }^{3}$ \\ Rubens Alves de Oliveira ${ }^{4}$
}

RESUMO

Avaliou-se, neste trabalho, o efeito da aplicação intensiva de esterco líquido de suínos (ELS), pelo método do escoamento superficial, nas características químicas de um solo Podzólico Vermelho-Amarelo cultivado com quatro espécies forrageiras: quicuio da Amazônia (Brachiaria humidicola (Rendle) Schweick), braquiária (Brachiaria decumbens Stapf), coastcross (Cynodon dactylon (L.) Pers.) e tifton 85 (Cynodon spp.). O ELS foi aplicado em parcelas de $4 m^{2}$ e com $5 \%$ de declividade, durante 4 meses, na taxa média equivalente a $800 \mathrm{~kg}$ $h a^{-1} d^{-1}$ de demanda bioquímica de oxigênio $\left(D B O^{5}\right)$. Para caracterização química, amostras de solo foram coletadas à profundidade de 0-0,20m, antes de iniciar o experimento e após o término dele. A aplicação de ELS proporcionou acúmulo de $\mathrm{P}, \mathrm{K}, \mathrm{Na}$ e Zn no solo, enquanto as concentrações de $\mathrm{Mg}$ e Cu diminuíram e a de Ca se manteve inalterada. Houve aumento na acidez, na soma de bases, na CTC e redução na saturação por bases. Devido ao acúmulo de nutrientes, recomenda-se monitoramento das características químicas do solo, ao longo de seu perfil e das águas subterrâneas para que se avaliem riscos de contaminação ambiental.

Palavras-chave: esterco líquido de suíno, tratamento por escoamento superficial, gramíneas forrageiras, disposição de resíduos no solo

\section{ABSTRACT}

In this study, the effect of intensive swine liquid manure (SLM) application was evaluated through the overland flow method, on chemical characteristics of a Yellow-red Podzolic soil (Ultisol) cultivated with four forage species: Amazonian kikuyu grass (Brachiaria humidicola (Rendle) Schweick), signal grass (Brachiaria decumbens Stapf), coastcross bermudagrass (Cynodon dactylon (L.) Pers.) and Tifton 85 bermudagrass (Cynodon spp.) were evaluated. SLM was applied in plots of $4 \mathrm{~m}^{2}$ and with $5 \%$ slope, during four months, at an average equivalent to $800 \mathrm{~kg} \mathrm{ha}^{-1} \mathrm{~d}^{-1}$ of biochemical oxygen demand $\left(B O D^{5}\right)$. Soil samples were collected at $0-0,20 \mathrm{~m}$ depth, in the beginning and at the end of the experiment.
The result showed the increase of the $P, K, N a$ and $Z n$ concentrations while the $\mathrm{Mg}$ and $\mathrm{Cu}$ concentrations decreased and Ca continued unaltered. The acidity, sum of bases and CEC increased in the soil that received SLM, while the saturation of bases decreased. Due to the nourishiment accumulation, it is recommended to monitor the soil chemical characteristcs and underground water on the profile for evaluation of the enviromental contamination risks.

Key words: swine liquid manure, overland flow, forage grasses, sewage disposal in the soil.

\section{INTRODUÇÃO}

A suinocultura tecnificada, por ser atividade altamente poluidora, tem nos últimos anos demandado pesquisas com vistas ao desenvolvimento de tecnologias adequadas e de baixo custo para o tratamento ou disposição das águas residuárias. A utilização do solo como meio depurador tem mostrado muitas vantagens, tanto de ordem técnica como econômica.

O solo, considerado um sistema disperso, polifásico e heterogêneo, possui propriedades que possibilitam sua utilização como meio de tratamento de águas residuárias. Este filtro natural, constituído pela matriz solo, com suas propriedades de adsorção química e física, pelas plantas e pelos microrganismos, pode atuar como depurador de águas residuárias por meio da intercepção dos sólidos em suspensão e remoção de nutrientes, além da oxidação do material orgânico promovido por bactérias que se estabelecem no próprio solo. Entretanto, para que a disposição de efluentes líquidos no solo não traga

\footnotetext{
${ }^{1}$ Engenheiro Agrícola, MSc, Engenharia Agrícola, Universidade Estadual de Goiás, Rua Couto Dafico Qd 51, Lt 43, Bairro Jundiaí, 75110-190, Anápolis, GO. Email: flmqueiroz@yahoo.com.br

${ }^{2}$ Professor Adjunto, Departamento de Engenharia Agrícola (DEA), Centro de Ciências Agrárias (CCA), Universidade Federal de Viçosa (UFV), 36571-000 Viçosa, MG, fone 0xx(31)3899-1886. Email: atmatos@mail.ufv.br

3Professor Adjunto, DZO, CCA, UFV, fone 0xx(31)3899 -3323. E mail: Odilon@mail.ufv.br

${ }^{4}$ Professor Adjunto, DEA, CCA, UFV, fone 0xx(31)3899-1909. Email: ralves@ mail.ufv.br
} 
riscos de salinização e contaminação ambiental, tornase necessário o conhecimento da capacidade de suporte de cada sistema solo-planta para que se possa estabelecer a taxa de aplicação mais adequada, de forma a resguardar a integridade dos recursos naturais (MATOS \& SEDIYAMA, 1995).

Estudos sobre os efeitos da aplicação de águas residuárias nas características químicas de solos têm sido realizado por vários pesquisadores. KING et al. (1985), aplicando o efluente de lagoa anaeróbia de suinocultura no capim-coastcross, nas taxas de 335, 670 e $1340 \mathrm{~kg}$ de $\mathrm{N} \mathrm{ha}^{-1}$ ano $^{-1}$, obtiveram aumento na concentração de P na superfície e de K, Na, Ca e Mg em profundidade. Resultados semelhantes foram obtidos por CAMPELO (1999), que avaliou a capacidade de um Podzólico Vermelho Amarelo, sem cobertura vegetal, em infiltrar águas residuárias de suinocultura com quatro diferentes concentrações de sólidos totais $\left(2,40 ; 7,00 ; 16,30\right.$ e $\left.26,90 \mathrm{~kg} \mathrm{~m}^{-3}\right)$ e encontrou aumento nas concentrações de $\mathrm{Ca}, \mathrm{Cu}, \mathrm{Zn}$ e P nas camadas superficiais do solo. Por outro lado, MATOS et al. (1997) não verificaram aumento nas concentrações de $\mathrm{Cu}$ e $\mathrm{Zn}$ trocáveis no perfil do solo submetido à aplicação de esterco líquido de suínos nas doses de $0,50,100,150$ e $200 \mathrm{~m}^{3}$ ha $^{-1}$, sendo que neste caso a aplicação foi efetuada, na sua totalidade, em uma só vez. CHATEAUBRIAND (1988) aplicou estas mesmas doses na cultura do milho por meio de irrigação por sulcos e observou tendência de aumento nas concentrações de $\mathrm{P}, \mathrm{K}$ e $\mathrm{S}$ disponíveis, na profundidade de 0 - 0,20m, na época da floração, o mesmo não ocorrendo no período da colheita.

Embora existam trabalhos que visam conhecer a capacidade de suporte de solos que receberam água residuária, nem todos utilizaram cobertura vegetal na área avaliada. Considerando que a planta tem participação fundamental na viabilidade técnica e sustentabilidade do sistema de tratamento, objetivou-se neste trabalho avaliar o efeito da aplicação intensiva de esterco líquido de suínos nas características químicas e físico-químicas de um solo Podzólico Vermelho-Amarelo, cultivado com diferentes gramíneas forrageiras.

\section{MATERIAL E MÉTODOS}

O experimento foi instalado na área experimental de Hidráulica, Irrigação e Drenagem do Departamento de Engenharia Agrícola, na Universidade Federal de Viçosa. O período de avaliação foi compreendido entre 29 de novembro de 1999 e 28 de março de 2000.

Em terreno arado e gradeado, foram delimitadas 32 parcelas de $4 \mathrm{~m}^{2}(2 \times 2 \mathrm{~m})$, com $5 \%$ de declividade, separadas por ruas de $1 \mathrm{~m}$ de largura, sendo as gramíneas forrageiras plantadas e os tratamentos aplicados definidos por sorteio.

O plantio das gramíneas forrageiras quicuio da Amazônia (Brachiaria humidicola (Rendle Schweick), braquiária (Brachiaria decumbens Stapf), coastcross (Cynodon dactylon (L.) Pers.) e tifton 85 (Cynodon spp.) foi feito com mudas, em sulcos de aproximadamente $0,15 \mathrm{~m}$ de profundidade, espaçados de 0,30 m entre linhas e $0,20 \mathrm{~m}$ entre plantas. Na ocasião da implantação, aplicaram-se $50 \mathrm{~kg} \mathrm{ha}^{-1}$ de superfosfato simples, no sulco de plantio.

O escoamento superficial sobre o solo foi feito com esterco líquido proveniente do setor de suinocultura da Universidade Federal de Viçosa e, nas parcelas testemunhas, utilizou-se água da rede de abastecimento, sendo ambas distribuídas por gravidade e em igual volume.

A estrutura hidráulica para armazenamento e distribuição de água nas parcelas foi constituída por reservatórios de amianto de $0,50 \mathrm{~m}^{3}$, posicionados $0,50 \mathrm{~m}$ acima da superfície do solo, e sistema de distribuição da água residuária nas parcelas. Na parte inferior dos reservatórios, conectou-se uma válvula de gaveta de $25,4 \mathrm{~mm}$, na qual foi adaptada uma tubulação de PVC do mesmo diâmetro, para conduzir a água até as mangueiras de distribuição. A aplicação de água no solo foi realizada com uso de mangueira de $63,5 \mathrm{~mm}$ de diâmetro e $2 \mathrm{~m}$ de comprimento, posicionada na parte superior das parcelas. Estas foram perfuradas a cada $0,10 \mathrm{~m}$, com furos de $8 \mathrm{~mm}$ de diâmetro e tiveram as laterais fechadas com tampão de madeira. A vazão aplicada foi de, aproximadamente, $0,002 \mathrm{~m}^{3} \mathrm{~s}^{-1}$, regulada pela abertura da válvula inserida na tubulação de alimentação de 25,4mm.

Em 29 de novembro de 1999, após corte de uniformização das gramíneas forrageiras, iniciouse a aplicação de esterco líquido de suínos (ELS) e água da rede de abastecimento nas parcelas. Esta ocorreu de forma intermitente, nos dias úteis e no período da manhã, sob uma taxa que, em média, foi equivalente a $800 \mathrm{~kg} \mathrm{ha}^{-1} \mathrm{~d}^{-1}$ de demanda bioquímica de oxigênio $\left(\mathrm{DBO}_{5}\right)$. Durante quatro meses, foi realizada amostragem periódica do esterco líquido para realização das análises químicas, físicas e bioquímicas pertinentes (APHA, 1995), possibilitando, assim, o cálculo do volume a ser aplicado. Na tabela 1, estão apresentados a quantidade média de nutrientes aplicados semanalmente e o total do período de experimentação.

Na tabela 2, estão apresentados os dados climáticos médios mensais de temperaturas máxima, 
Tabela 1 - Lâmina média semanal aplicada e estimativa da quantidade de cada nutriente aplicado semanalmente e ao longo de todo o período de experimentação.

\begin{tabular}{lcccccccccc}
\hline & Lâmina & N total & K & Na & Ca & $\mathrm{Mg}$ & $\mathrm{Zn}$ \\
\hline & \multicolumn{1}{c}{$\mathrm{mm}$} \\
Média semanal & 276,72 & 1309,95 & 680,09 & 319,44 & 112,86 & 1198,89 & 134,05 & 108,64 & 8,78 \\
Total aplicado $\left(\mathrm{x} 10^{3}\right)^{1}$ & 44,20 & 20,96 & 10,88 & 5,11 & 1,80 & 19,18 & 2,14 & 1,74 & 0,14 \\
\hline
\end{tabular}

${ }^{1 /}$ Total = média $\mathrm{x}$ número de semanas do experimento (16)

média e mínima, umidade relativa, e totais semanais de precipitação pluvial e insolação fornecidos pelo Laboratório de Meteorologia do Departamento de Engenharia Agrícola da UFV. No período experimental, a temperatura máxima foi de $30,7^{\circ} \mathrm{C}$ e a mínima de $17,3^{\circ} \mathrm{C}$, enquanto a umidade relativa do ar variou de 72,6 a $88,8 \%$ e a precipitação total foi de $642,1 \mathrm{~mm}$.

O solo local, classificado como Podzólico Vermelho-Amarelo, foi amostrado com uso de trado holandês, na profundidade de 0 a $0,20 \mathrm{~m}$ em três épocas distintas: antes do plantio, antes de iniciar o experimento e após o término deste. Antes do plantio, as parcelas não estavam delimitadas, sendo retiradas amostras em cinco pontos distintos da área total, formando assim uma amostra composta, da qual se retiraram subamostras que foram encaminhadas ao Laboratório de Física, Química e Fertilidade do Solo da Universidade Federal de Viçosa. Nas duas amostragens seguintes, três amostras foram retiradas de cada parcela sendo estas analisadas no Laboratório de Análise de Solo Viçosa. Em todos os casos, as amostras foram secadas ao ar, homogeneizadas, destorroadas e passadas em peneira de $2 \mathrm{~mm}$ de malha, sendo a concentração de $\mathrm{P}$ disponível, $\mathrm{Na}$ e $\mathrm{K}$ trocáveis determinada com extrator Mehlich $1 \mathrm{com}$ colorímetro e fotometria de chama, respectivamente, $\mathrm{Ca}, \mathrm{Mg}$ trocáveis $\left(\mathrm{KCL}_{1} \mathrm{molL}^{-1}\right), \mathrm{Cu}$ e $\mathrm{Zn}$ trocáveis (Mehlich 1) por espectrofotometria de absorção atômica, $\mathrm{Al}^{3+}$ trocável (KCL $1 \mathrm{~mol} \mathrm{~L}^{-1}$ ) e acidez potencial (acetato de cálcio $0,5 \mathrm{~mol} \mathrm{~L}^{-1}$ ) por titulometria e o $\mathrm{pH}\left(\mathrm{H}_{2} \mathrm{O}\right)$ foi determinado em potenciômetro (EMBRAPA, 1997). A soma de bases trocáveis e o índice de saturação por bases foram obtidos por cálculo enquanto a CTC foi obtida pelo método da soma de bases trocáveis. Na análise física, obtiveram-se 210, 140, 60 e $590 \mathrm{~g} \mathrm{~kg}^{-1}$ de areia grossa, areia fina, silte e argila, respectivamente, resultando na classificação textural de argila.

Os resultados foram analisados segundo o arranjo experimental de parcelas subdivididas, sendo as parcelas constituídas pelo esquema fatorial $4 \times 2$, quatro espécies forrageiras (quicuio da Amazônia, braquiária, coastcross e tifton 85) e duas qualidades de água aplicadas (residuária e da rede de abastecimento) e as subparcelas, constituídas pelas épocas de amostragem, analisadas segundo o delineamento em blocos casualizados, com quatro repetições. De acordo com o resultado da análise de variância, procedeu-se ao teste de médias Tukey $(\mathrm{P}<$ $0,01)$ para diferenciação entre os atributos químicos avaliados.

\section{RESULTADOS E DISCUSSÃO}

Verificou-se, mediante análise de variância, que a concentração dos nutrientes $\mathrm{P}, \mathrm{K}, \mathrm{Na}$, $\mathrm{Zn} \mathrm{e} \mathrm{Cu}$, no solo, foi influenciada pela interação entre tratamento e pela época de amostragem, sendo que somente o K variou também em função da gramínea forrageira, já a concentração de Ca foi influenciada exclusivamente pelo tratamento, enquanto o Mg pela época de amostragem.

O resultado do teste de médias referente à interação entre tratamento e época de amostragem (Tabela 3) mostra que, antes do início do experimento,

Tabela 2 - Médias mensais de temperatura e umidade relativa do ar (UR) e totais mensais de precipitação (PREC) e insolação (INS), durante o período experimental, em Viçosa, MG.

\begin{tabular}{|c|c|c|c|c|c|c|}
\hline \multirow{2}{*}{ Período } & \multicolumn{3}{|c|}{ Temperaturas médias $\left({ }^{\circ} \mathrm{C}\right)$} & \multirow{2}{*}{$\frac{\mathrm{UR}}{(\%)}$} & \multirow{2}{*}{$\frac{\text { PREC }}{(\mathrm{mm})}$} & \multirow{2}{*}{$\frac{\text { INS }}{\text { (h) }}$} \\
\hline & Máx & Média & Mín & & & \\
\hline $12 / 1999$ & 27,5 & 22,3 & 18,8 & 79,9 & 144,3 & 151,1 \\
\hline $01 / 2000$ & 28,6 & 22,8 & 19,1 & 80,4 & 223,8 & 159,1 \\
\hline $02 / 2000$ & 28,7 & 22,6 & 18,6 & 81,7 & 179,1 & 162,0 \\
\hline $03 / 2000$ & 27,6 & 22,0 & 18,3 & 83,0 & 94,9 & 144,1 \\
\hline
\end{tabular}

Ciência Rural, v.34, n.5, set-out, 2004. 
as concentrações de $\mathrm{P}, \mathrm{K}, \mathrm{Na}, \mathrm{Cu}$ e $\mathrm{Zn}$ eram semelhantes $(\mathrm{P}<0,01)$ entre as parcelas. Ao final do período de experimentação, ao contrário, o solo das parcelas que receberam ELS apresentou maiores concentrações de $\mathrm{P}$ disponível e K, Na e Zn trocáveis que o solo que recebeu água da rede, o mesmo não acontecendo com o cobre trocável.

Ao se comparar época de amostragem, verifica-se que as concentrações de $\mathrm{P}$ disponível e $\mathrm{K}$, Na e Zn trocáveis aumentaram com a aplicação de ELS. CAMPELO (1999) obteve resultado semelhante na camada superficial para P, K e Zn. KING et al. (1985) obtiveram resultados semelhantes para $\mathrm{P}$ e CHATEAUBRIAND (1988), para Pe K. Segundo Pratt (1979), citado por OLIVEIRA (1993), o acúmulo de $\mathrm{P}$ e K pelo uso de grandes quantidades de dejetos de animais, por longos períodos, pode causar desbalanço de nutrientes, como é o caso do sintoma de deficiência de magnésio em plantas, devido ao excesso de potássio no solo. Segundo os mesmos autores, estes efeitos, porém, só se apresentam após décadas de aplicação contínua de resíduos orgânicos.

O cobre, diferentemente do encontrado para outros nutrientes, teve sua concentração diminuída em ambos os tratamentos, indicando que este mineral, tal como foi verificado por MATOS et al. (1997), além de em parte extraído pela cultura, tornou-se menos disponível em razão da complexação pela matéria orgânica do solo que era adicionada com o ELS, tornando-se, dessa forma, não extraível com extratores fracos. CAMPELO (1999) verificou acúmulo deste metal na camada superficial do solo, entretanto, no trabalho deste autor, o solo não estava coberto com vegetação.

Nas parcelas que receberam água da rede de abastecimento não houve diferença significativa para as concentrações de $\mathrm{P}$ disponível e $\mathrm{Na}$ e $\mathrm{Zn}$ trocáveis, em função da época de amostragem, exceto os nutrientes $\mathrm{K}$ e $\mathrm{Cu}$ que sofreram significativo decréscimo em sua concentração no solo, possivelmente em razão da utilização destes nutrientes pelas plantas (Tabela 3 ).

A concentração de potássio no solo variou também em função da gramínea forrageira, conforme se verifica na tabela 4 , registrando-se maior acúmulo nas parcelas cultivadas com os capins tifton 85, coastcross e quicuio da Amazônia. As parcelas cultivadas com o capim-braquiária foram as que menos acumularam este nutriente no solo. Talvez isto se deva a uma maior capacidade de extração de K por este capim em relação aos demais.

A concentração de cálcio no solo variou com a qualidade de água aplicada. Os resultados do
Tabela 3 - Valores médios de fósforo disponível (P) e potássio $(\mathrm{K})$, sódio $(\mathrm{Na})$, cobre $(\mathrm{Cu})$ e zinco $(\mathrm{Zn})$ trocáveis, no solo das parcelas que receberam esterco líquido de suínos (ELS) e água da rede de abastecimento, obtidos em duas épocas: anterior ao início e após o término do experimento

\begin{tabular}{llll}
\hline & $\begin{array}{l}\text { Qualidade } \\
\text { da água }\end{array}$ & Início & Término \\
\hline $\mathrm{P}\left(\mathrm{mg} \mathrm{dm}^{-3}\right)$ & ELS & $31,45 \mathrm{Ba}$ & $85,28 \mathrm{Aa}$ \\
& Água & $24,10 \mathrm{Aa}$ & $24,73 \mathrm{Ab}$ \\
$\mathrm{K}\left(\mathrm{mg} \mathrm{dm}^{-3}\right)$ & ELS & $126,68 \mathrm{Ba}$ & $206,06 \mathrm{Aa}$ \\
& Água & $126,68 \mathrm{Aa}$ & $76,00 \mathrm{Bb}$ \\
$\mathrm{Na}\left(\mathrm{mg} \mathrm{dm}^{-3}\right)$ & ELS & $10,06 \mathrm{Ba}$ & $23,43 \mathrm{Aa}$ \\
& Água & $9,68 \mathrm{Aa}$ & $9,00 \mathrm{Ab}$ \\
$\mathrm{Cu}\left(\mathrm{mg} \mathrm{dm}^{-3}\right)$ & ELS & $12,58 \mathrm{Aa}$ & $7,88 \mathrm{Ba}$ \\
& Água & $15,21 \mathrm{Aa}$ & $7,13 \mathrm{Ba}$ \\
$\mathrm{Zn}\left(\mathrm{mg} \mathrm{dm}^{-3}\right)$ & ÉS & $11,94 \mathrm{Ba}$ & $22,66 \mathrm{Aa}$ \\
& Água & $10,67 \mathrm{Aa}$ & $10,30 \mathrm{Ab}$ \\
\hline
\end{tabular}

As médias seguidas por mesma letra, maiúscula nas linhas e minúsculas nas colunas, não diferem entre si, a $1 \%$ de probabilidade, pelo teste Tukey.

teste de médias indicam que o solo que recebeu esterco líquido de suínos teve, ao final do período de experimentação, a concentração de Ca trocável significativamente aumentada $\left(4,48 \mathrm{cmol}_{\mathrm{c}} \mathrm{dm}^{-3}\right) \mathrm{em}$ relação ao solo tratado com água da rede de abastecimento $\left(3,88 \mathrm{cmol}_{\mathrm{c}} \mathrm{dm}^{-3}\right)$.

A concentração de magnésio trocável no solo foi influenciada pelo tempo de aplicação, sendo estatisticamente maior no início do experimento $\left(1,17 \mathrm{cmol}_{\mathrm{c}} \mathrm{dm}^{-3}\right)$ que no final $\left(1,01 \mathrm{cmol}_{\mathrm{c}} \mathrm{dm}^{-3}\right)$, possivelmente devido à extração pelas plantas.

As características do solo relacionadas com a CTC, apresentadas na tabela 5, mostram que antes de iniciar o experimento o solo estava em boas condições, no que se refere à soma e saturação por bases, CTC a pH 7,0 e CTC efetiva, caracterizadas, segundo a CFSEMG (1989), respectivamente como alta, média e média. Ao final do período de experimentação, o solo tratado com água da rede de abastecimento apresentou a tendência de diminuição da soma de bases e, conseqüentemente, da CTC (determinada pelo método de soma de bases) e

Tabela 4 - Concentração média de potássio trocável no solo das parcelas cultivadas com as diferentes gramíneas, submetidas à aplicação de esterco líquido de suínos e água da rede de abastecimento.

\begin{tabular}{lcc}
\hline \multicolumn{1}{c}{ Gramíneas forrageiras } & \multicolumn{2}{c}{$\mathrm{K}\left(\mathrm{mg} \mathrm{dm}^{-3}\right)$} \\
\hline Quicuio da Amazônia & 137,43 & $\mathrm{AB}$ \\
Braquiária & 110,43 & $\mathrm{~B}$ \\
Tifton 85 & 152,31 & $\mathrm{~A}$ \\
Coastcross & 135,25 & $\mathrm{AB}$ \\
\hline
\end{tabular}

As médias seguidas por mesma letra não diferem entre si, a $1 \%$ de probabilidade, pelo teste Tukey.

Ciência Rural, v.34, n.5, set-out, 2004. 
Tabela 5 - Características químicas e físico-químicas na camada superficial do solo $(0$ - 0,20m) que recebeu esterco líquido de suínos (ELS) e água da rede de abastecimento, em diferentes épocas.

\begin{tabular}{|c|c|c|c|c|c|}
\hline \multicolumn{6}{|c|}{ Características químicas e físico-químicas } \\
\hline & \multirow{3}{*}{$\begin{array}{l}\text { Antes do } \\
\text { Plantio }\end{array}$} & \multirow{2}{*}{\multicolumn{2}{|c|}{$\begin{array}{l}\text { Início do experimento } \\
\qquad 29 / 10 / 1999\end{array}$}} & \multirow{2}{*}{\multicolumn{2}{|c|}{$\begin{array}{l}\text { Término do experimento } \\
\qquad 29 / 03 / 2000\end{array}$}} \\
\hline & & & & & \\
\hline & & ELS & Água & ELS & Água \\
\hline${ }^{1 /} \mathrm{pH}$ & 5,90 & 6,40 & 6,20 & 5,70 & 6,30 \\
\hline${ }^{2 /} \mathrm{P}\left(\mathrm{mg} \mathrm{dm}^{-3}\right)$ & 20,40 & 31,45 & 24,10 & 85,28 & 24,73 \\
\hline${ }^{2 /} \mathrm{K}^{+}\left(\mathrm{mg} \mathrm{dm}^{-3}\right)$ & 68,00 & 126,68 & 126,68 & 206,06 & 76,00 \\
\hline${ }^{2 /} \mathrm{Na}^{+}\left(\mathrm{mg} \mathrm{dm}^{-3}\right)$ & - & 10,06 & 9,68 & 23,43 & 9,00 \\
\hline${ }^{3 /} \mathrm{Ca}^{2+}\left(\mathrm{cmol}_{\mathrm{c}} \mathrm{dm}^{-3}\right)$ & 3,90 & 4,37 & 3,84 & 4,61 & 3,94 \\
\hline${ }^{3 /} \mathrm{Mg}^{2+}\left(\mathrm{cmol}_{\mathrm{c}} \mathrm{dm}^{-3}\right)$ & 1,30 & 1,21 & 1,14 & 1,04 & 0,99 \\
\hline${ }^{2 /} \mathrm{Zn}^{2+}\left(\mathrm{mg} \mathrm{dm}^{-3}\right)$ & - & 11,94 & 10,67 & 22,66 & 10,30 \\
\hline${ }^{2 /} \mathrm{Cu}^{2+}\left(\mathrm{mg} \mathrm{dm}^{-3}\right)$ & - & 12,58 & 15,21 & 7,88 & 7,13 \\
\hline${ }^{3 /} \mathrm{Al}^{3+}\left(\mathrm{cmol}_{\mathrm{c}} \mathrm{dm}^{-3}\right)$ & 0,00 & 0,00 & 0,00 & 0,18 & 0,00 \\
\hline${ }^{4 /} \mathrm{H}+\mathrm{Al}\left(\mathrm{cmol}_{\mathrm{c}} \mathrm{dm}^{-3}\right)$ & 3,30 & 2,34 & 2,67 & 3,69 & 2,68 \\
\hline${ }^{5 /} \mathrm{SB}\left(\mathrm{cmol}_{\mathrm{c}} \mathrm{dm}^{-3}\right)$ & 5,37 & 5,94 & 5,35 & 6,28 & 5,16 \\
\hline${ }^{6 /} \mathrm{CTC}_{\mathrm{c}}\left(\mathrm{cmol}_{\mathrm{c}} \mathrm{dm}^{-3}\right)$ & 5,37 & 5,94 & 5,35 & 6,46 & 5,16 \\
\hline${ }^{7 /} \mathrm{CTC}_{\mathrm{p}}\left(\mathrm{cmol}_{\mathrm{c}} \mathrm{dm}^{-3}\right)$ & 8,67 & 8,28 & 8,02 & 9,97 & 7,84 \\
\hline${ }^{8 /} \mathrm{V}(\%)$ & 61,94 & 71,74 & 66,70 & 62,98 & 65,81 \\
\hline${ }^{9 /} \mathrm{m}(\%)$ & 0,00 & 0,00 & 0,00 & 2,78 & 0,00 \\
\hline
\end{tabular}

${ }^{1 /} \mathrm{pH}$ em água, relação 1:2,5, ${ }^{2 /}$ Extrator Mehlich $1,{ }^{3 /}$ Extrator: $\mathrm{KCl}-1 \mathrm{~mol} \mathrm{~L}{ }^{-1} ;{ }^{4 /}$ Extrator acetato de cálcio $0,5 \mathrm{~mol} \mathrm{~L}{ }^{-1}-\mathrm{pH} 7,0 ;{ }^{5 /}$ Soma de bases trocáveis; ${ }^{6 /}$ Capacidade de troca catiônica efetiva; ${ }^{7 /}$ Capacidade de troca catiônica a pH 7,$0 ;{ }^{8 /}$ Índice de saturação por bases; ${ }^{9 /}$ Índice de saturação por alumínio.

saturação por bases, possivelmente, em razão da extração de nutrientes do solo pelas plantas. O solo que recebeu esterco líquido de suínos teve aumentada sua acidez, soma de bases e CTC. O aumento na soma de bases foi devido ao aumento de potássio, e a redução no $\mathrm{pH}$ deve ter causado a redução na saturação por bases e o aumento do alumínio trocável. Os resultados confirmam o enriquecimento do solo que recebeu o esterco líquido de suínos, entretanto, ressalta-se que os impactos negativos desta aplicação sobre o solo e águas subterrâneas estão condicionados às características do solo, como a textura (BURNS, et al., 1985), ao tipo de cultura explorada e às condições climáticas locais (LOEHR, 1984).

\section{CONCLUSÃO}

Os nutrientes P, K, Na e Zn aplicados com o esterco líquido de suínos, acumularam no solo, na profundidade de $0-0,20 \mathrm{~m}$, sendo recomendável um monitoramento das características químicas do solo, ao longo de seu perfil e das águas subterrâneas para que se avaliem riscos de contaminação ambiental.

O solo que recebeu esterco líquido de suínos teve aumento na soma de bases, CTC e alumínio trocável e decréscimo do $\mathrm{pH}$ e da saturação por bases.

\section{REFERÊNCIAS BIBLIOGRÁFICAS}

APHA. AMERICAN PUBLIC HEALTH ASSOCIATION. Standard methods for the examination of water and wastewater. 19.ed. New York : APHA, WWA, WPCR, 1995.

BURNS, J.C. et al. Swine lagoon effluent applied to "Coastal"Bermudagrass: 1. Forage yield, quality and element removal. Journal of Environmental. Quality, v.14, n.1, p.9$14,1985$.

CAMPELO, P.L.G. Influência da aplicação de águas residuárias de suinocultura nas características físico-hídricas e químicas de um solo Podzólico Vermelho-Amarelo. 1999. 55f. Dissertação (Mestrado em Engenharia Agrícola) - Curso de pós-graduação em Engenharia Agrícola, Universidade Federal de Viçosa.

CFSEMG. COMISSÃO DE FERTILIDADE DO SOLO DO ESTADO DE MINAS GERAIS. Recomendação para o uso de corretivos e fertilizantes em Minas Gerais. 4.apr. Lavras, MG, 1989. 176p.

CHATEAUBRIAND, A.D. Efeito de esterco líquido de suínos, aplicados em irrigação por sulco, na cultura do milho (Zea mays L.). 1988. 61f. Dissertação (Mestrado em Engenharia Agrícola) - Curso de pós-graduação em Engenharia Agrícola, Universidade Federal de Viçosa.

EMBRAPA. CENTRO NACIONAL DE PESQUISA DE SOLOS. Manual de métodos de análise de solos. 2.ed. Rio de Janeiro : EMBRAPA, 1997. 212p. (EMBRAPACNPS, Documentos, 1). 
KING, L.D. et al. Swine lagoon effluent applied to 'Coastal' Bermudagrass: II. Effects on soil. Journal of Environmental Quality, v.14, n.1, p.14-21, 1985.

LOEHR, R.C. Agricultural waste, manegement: problems, processes and approaches. New York: n.i., 1984. 590p.

MATOS, A.T.; SEDIYAMA, M.A.N. Riscos potenciais ao ambiente pela aplicação de esterco líquido de suínos ou compostos orgânicos no solo. In: SEMINÁRIO MINEIRO
SOBRE MANEJO E UTILIZAÇÃO DE ESTERCO LÍQUIDO DE SUÍNOS, 1., 1995, Ponte Nova. Anais... Viçosa, MG: EPAMIG, 1995. p.45-54.

MATOS, A.T. et al. Características químicas e microbiológicas do solo influenciadas pela aplicação de esterco líquido de suínos. Revista CERES, v.44, n.254, p.399-410, 1997.

OLIVEIRA, P.A.V. Manual de manejo e utilização dos dejetos de suínos. Concórdia : EMBRAPA, CNPSA, 1993. 188p. (EMBRAPA/CNPSA, Documentos, 27). 